\title{
Yiu-Wai Chu, Hong Kong Cantopop: A Concise History,
}

Hong Kong, Hong Kong University Press, 2017, 256 pp.

\section{Nathanel Amar}

\section{(2) OpenEdition}

\section{Journals}

Electronic version

URL: http://journals.openedition.org/chinaperspectives/7493

DOI: $10.4000 /$ chinaperspectives.7493

ISSN: 1996-4617

\section{Publisher}

Centre d'étude français sur la Chine contemporaine

\section{Printed version}

Date of publication: 1 December 2017

Number of pages: $63-64$

ISSN: 2070-3449

\section{Electronic reference}

Nathanel Amar, «Yiu-Wai Chu, Hong Kong Cantopop: A Concise History, », China Perspectives [Online], 2017/4 | 2017, Online since 01 December 2017, connection on 24 September 2020. URL : http:// journals.openedition.org/chinaperspectives/7493; DOI : https://doi.org/10.4000/chinaperspectives. 7493

This text was automatically generated on 24 September 2020.

(c) All rights reserved 


\title{
Yiu-Wai Chu, Hong Kong Cantopop: A Concise History,
}

Hong Kong, Hong Kong University Press, 2017, 256 pp.

\author{
Nathanel Amar
}

1 Yiu-Wai Chu, director of the Hong Kong Studies Program at the University of Hong Kong, continues in Hong Kong Cantopop: A Concise History the analyses he outlined in his previous book, published in 2013, Lost In Transition: Hong Kong Culture in the Age of China. ${ }^{1}$ Like Lost In Transition, this book is haunted by the decline of Hong Kong culture since the handover, and by the spectre of mainland China. By offering a chronological history of Hong Kong popular music, Yiu-Wai Chu's book emerges as a reference in Asian Cultural Studies in English.

2 The introduction (pp. 1-20) reviews the notion of "Cantopop," a term that emerged in the late 1970 s to describe popular music in Cantonese produced in Hong Kong. For the author, Cantopop lies

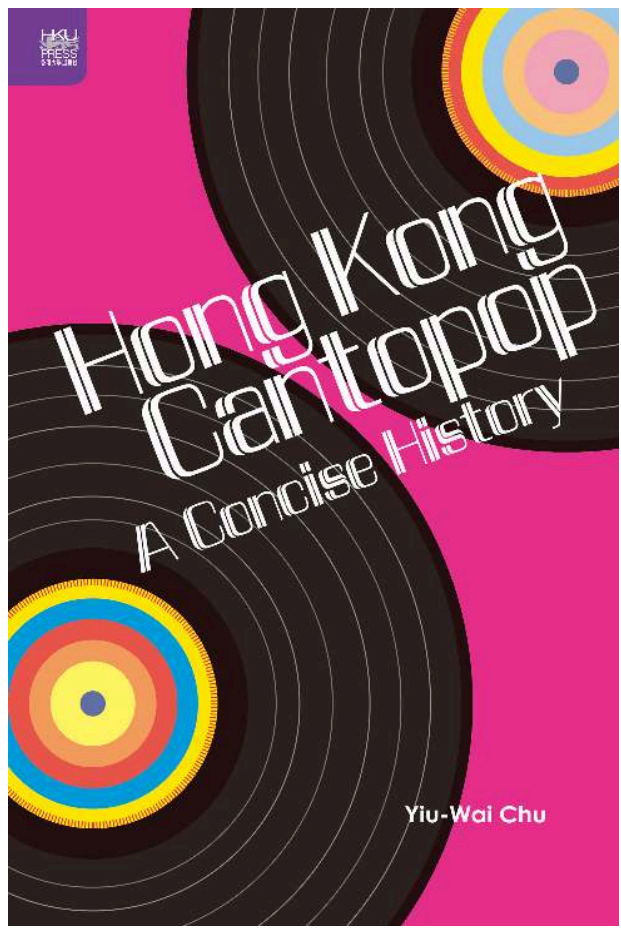
at the intersection of the two traditional definitions of pop music, as it is both "the main commercially produced and marketed musical genre" (p. 3) and popular in the sense that it is "capable of uniting a variety of social groups" (p. 4). This fairly wide definition of pop allows Chu to not contrast Cantopop too strongly with rock and alternative music-which are present at the margins throughout the book. The author justifies his focus on Cantopop in view of the limited existing English language studies on Hong Kong folk music: "Academic work on 
Chinese popular music shows a bias toward rock music from Beijing rather than pop music from either Hong Kong or Taiwan" (p. 10). The present work is thus an introduction to Cantopop. This leads the author to leave aside the study of the lyrics of songs, which, while regrettable, is justified by the global economy of the book.

3 The second part of the book (pp. 21-39) challenges the representations traditionally associated with Cantopop, by making a genealogy of it even before the appearance of the term. Until 1974, Cantopop was marginalised in the colonial society of Hong Kong, with music and the Cantonese language being perceived as inferior to English and Mandarin. Popular music in Cantonese was thus considered a "working-class pastime" (p. 21), which most often dealt with the difficulties of daily life during colonisation.

4 The rise of Cantopop in the 1970s is the subject of the book's third part (pp. 40-68), concomitant with the identity and social claims born of the workers' revolts of 1967 and the extension of the market in the 1970s. The year 1974 marks a turning point in the history of Cantopop, with the broadcast on TVB (Television Broadcasts Limited) of the series A Love Tale between Tears and Smiles, the Cantonese theme song of which was hugely successful. The author shows the close links between Cantopop and other cultural forms, such as television and cinema. The 1970s saw the emergence of many singers and lyricists who made it possible for Cantopop to develop, such as Sam Hui, "the God of Cantopop" (p. 48), who took up social problems in songs using vernacular language. Composer Joseph Koo and lyricist James Wong also participated in the popularisation of Cantopop through their songs for the television series Jade Theater. James Wong, nicknamed "the Godfather of Cantopop," was also to make Cantopop the subject of his thesis, defended in 2003 at the University of Hong Kong, ${ }^{2}$ and which serves as a reference throughout Yiu-Wai Chu's book. The popularity of Cantopop pushed the music industry in Hong Kong to turn to Cantonese. Singers who hitherto sang in Mandarin or made covers of English hits began producing songs in Cantonese, giving Cantopop the hybrid aspect that would make it successful.

The 1980s, described in the fourth part, represent the golden age of Cantopop (pp. 69-104), as well as its cultural hegemony on the Asian scene during the period of economic reforms in mainland China. The popularity of the song "The Bund," from the eponymous television series, sung in 1980 by Frances Yip with music by Joseph Koo and lyrics by James Wong, went well beyond the borders of Hong Kong and was even translated into Mandarin and Thai. During this decade, the first "superstars" appeared, such as Alan Tam, Leslie Cheung, and Anita Mui, who initiated a wave of unprecedented concerts. More than mere commercial events, these concerts "became a venue for building a collective memory for Hong Kong people" (p. 84). It is also the period when a limited but very influential Cantonese alternative music scene developed, including the rock bands Beyond and Tat Ming Pair, whose songs contain subversive political messages. The Tiananmen Square massacre in 1989 profoundly marked Cantopop, prompting singers, even the most popular ones, to pose the question of the future of China and Hong Kong in their songs.

6 The fifth part of the book focuses on the 1990s (pp. 105-144), in which the decline of Cantopop began, although it enjoyed a prosperous period at the beginning of the decade with the "Four Heavenly Kings"-Andy Lau, Jacky Cheung, Leon Lai, and Aaron Kwok, and the "Four Heavenly Queens"-Sally Yeh, Cass Phang, Sammy Cheng, and Kelly Chen. These singers were to dominate the Asian musical and visual scene in the 1990s, but this was not enough to stop the more general decline of Cantopop in the face 
of the development of Mandapop-popular music in Mandarin-from Mainland China and Taiwan. This shift is illustrated by the journey of the singer Faye Wong, born in Beijing, who became famous after settling in Hong Kong in 1987 by singing Cantopop before returning to Mandapop in the late 1990s. The slow decline of Cantopop was accompanied by a crisis of Hong Kong identity as retrocession approached, expressed in 1997 by a song that reeked of nationalism, "Chinese" ("Zhongguo ren") by Andy Lau, sung in Mandarin.

7 The last part (pp. 145-183) deals with the Cantopop crisis, which began in the noughts. In addition to declining sales, the world of Cantopop lost two of its most popular representatives in 2003, Leslie Cheung and Anita Mui, while the SARS epidemic hit the Hong Kong economy hard that same year. The promotion of four new Heavenly Kings, Andy Hui, Edmond Leung, Hacken Lee, and Leo Ku, did not enable Cantopop to resist the domination of Mandapop. Cantopop nevertheless followed the evolution of society, and some groups took a stand in support of the Umbrella Movement in 2014, such as Denise Ho, Anthony Yiu-Ming Wong, and Kat Tse, who sang the anthem of the movement, "Raise the Umbrella." In the midst of an identity crisis, Hong Kongers also turned to other forms of music, such as hip-hop with the collective Lazy Motha Fucka (LMF), while the record labels were no longer investing in new singers, preferring to recycle the old glories of Cantopop.

Yiu-Wai Chu's book opens new perspectives in Asian cultural studies, including a comparative approach to popular music in mainland china. The author provides some very interesting analyses of the queer genre and the queer imagination of Cantopop, but one is surprised when he states that "Leslie Cheung never openly declared his sexual orientation" (p. 135), nor does he mention TVB's censorship of homoerotic clips produced by Cheung. ${ }^{3}$ Moreover, the scandal provoked in 2008 by the diffusion of pornographic photos taken by the actor Edison Chen in the company of popular Cantopop singers is barely mentioned. ${ }^{4}$ The book's aim to write a history of Cantopop, which undoubtedly fills one of the gaps in Chinese studies, neglects the mainland's popular music, whether inspired by or critical of Cantopop. The book therefore encourages future research on the relationship between Cantopop and Chinese rock in the 1990s, for example through the concert given in front of 8,000 people by He Yong, Tang Dynasty, Dou Wei, and Zhang Chu on December 17, 1994 in the Hong Kong Coliseum, during which He Yong called the Four Heavenly Kings "clowns" and insulted Cantopop. ${ }^{5}$ Similarly, the author's desire to deal with Hong Kong alternative music at the same time as Cantopop forces him to bring together bands as diverse as the hip-hop collective LMF, the subversive anti-folk group My Little Airport, or the hardcore-punk band King Ly Chee, all of which deserve to be further analysed. Unfortunately, there are typos in the names of some Mainland singers and song titles, as well as repetitions in the body of the text.

9 Hong Kong Cantopop nevertheless remains an essential book for Asian cultural studies. In addition to a very complete chronology of Cantopop, accompanied by an excellent appendix, Yiu-Wai Chu's book makes it possible to place Hong Kong pop music in its geopolitical, cultural, and social context. Also to be appreciated is the effort of systematic transcription of the names of singers and songs in Chinese characters. This is an important book for understanding the construction of Hong Kong identity, which more generally enables taking popular music seriously, and deconstructs many prejudices about Cantopop. 


\section{NOTES}

1. Chu Yiu-Wai, Lost in Transition: Hong Kong Culture in the Age of China, Albany, State University of New York Press, 2013.

2. James Wong, The Rise and Decline of Cantopop: A Study of Hong Kong Popular Music (1949-1997), PhD Thesis, Hong Kong, University of Hong Kong, 2003.

3. Natalia Sui-hung Chan, "Queering Body and Sexuality: Leslie Cheung' s Gender Representation in Hong Kong Popular Culture," in Yau Ching (ed.), As Normal As Possible: Negotiating Sexuality and Gender in Mainland China and Hong Kong, Hong Kong, Hong Kong University Press, 2010, p. 147.

4. It was the subject of a chapter in the book by Jeroen de Kloet and Yiu Fai Chow, Sonic Multiplicities. Hong Kong Pop and the Global Circulation of Sound and Image, Chicago, Intellect, 2013, pp. 81-100.

5. Mike Levin, "Chinese Pop Music Lovers Show A Taste For Rock," Billboard, 21 January 1995, p. 45.

\section{AUTHOR}

\section{NATHANEL AMAR}

Nathanel Amar, Ph.D. in Political Science, is currently a postdoctoral fellow at the Society of Fellows in the Humanities of the University of Hong Kong (namar@hku.hk). 